\title{
ANALISIS INFORMASI CITRA ANATOMI ANTARA TEKNIK BREATH-HOLD DAN TRIGGER PADA PEMERIKSAAN MAGNETIC RESONANCE CHOLANGIOPANCREATOGRAPHY (MRCP) MENGGUNAKAN SEQUENCE T2 HALF FOURIER ACQUISITION SINGLE SHOT TSE (HASTE) CORONAL SLAB
}

\section{ANALYSIS OF IMAGE INFORMATION OF BREATH-HOLD AND TRIGGER TECHNIQUE IN MAGNETIC RESONANCE CHOLANGIOPANCREATOGRAPHY (MRCP) EXAMINATION USING T2 HALF FOURIER ACQUISITION SINGLE SHOT TSE (HASTE) SEQUENCE CORONAL SLAB}

\author{
Yusron Adi Utomo ${ }^{1)}$, Bambang Satoto ${ }^{2)}$, Rini Indrati ${ }^{3)}$ \\ 1) Technologist in Gunung Jati Cirebon Hospital \\ ${ }^{2)}$ Physician in Kariadi Semarang Hospital \\ ${ }^{3)}$ Health Polytechnics of Semarang-Indonesia \\ Author Mail: yusronadi17@gmail.com
}

\begin{abstract}
Background: There are two image acquisition techniques in MRCP examination, which are breath-hold and trigger technique. Acquisition process in breath hold occurs when the patient holds their breath, meanwhile trigger technique uses respiratory gatting that functioned to monitor patient's respiration and the acquisition occurs in the transition phase of inspiration and expiration. In Royal Taruma Jakarta Hospital this two technique are used sustainably, but in other hospital, such as Hasan Sadikin Bandung Hospital just uses one technique. This research aims to know the difference of anatomic image information of breath-hold and trigger technique in MRCP examination using T2 HASTE sequence coronal slab and to know which examination technique is better to produce anatomic image information between breath-hold and trigger technique.

Methods: This research type was quantitative research with the observational approach. The data obtained by scanning 10 patients using breath-hold and trigger technique in Royal Taruma Jakarta Hospital. The image result was scored by radiology physician using checklist. The obtained data was analyzed with Wilcoxon test to know the difference of anatomic image information and which technique is better to produce anatomic image information between breath-hold and trigger technique.

Results: The result showed that there were differences of anatomic image information of breath-hold and trigger technique on MRCP examination using T2 HASTE sequence coronal slab with p-value 0,011. Trigger technique produced better anatomic image information than breath-hold technique.

Conclusion: There were differences of anatomic image information of breath hold and trigger technique on MRCP examination using T2 HASTE sequence coronal slab. Trigger technique produced better anatomic image information than breath-hold technique.
\end{abstract}

Keywords: MRCP, trigger technique, breath-hold technique, T2 HASTE sequence, coronal slab

\section{PENDAHULUAN}

Magnetic Resonance Cholangio Pancreatography $(M R C P)$ adalah pemeriksaan MRI yang digunakan untuk mengevaluasi duktus billiaris, pankreas dan kandung empedu dengan salurannya karena kemungkinan adanya batu, tumor dan penyakit lainnya. MRCP merupakan pemeriksaan dengan gambaran multiplanar yang diperoleh dengan mensejajarkan biliary tree menggunakan Magnetic Resonance sekuens yang sensitif untuk menampakkan aliran tanpa menggunakan kontras agent. Aliran dalam duktus akan tampak terang dan sebaliknya jaringan lunak terlihat menjadi gelap (Mandarano, 2008).

Pemeriksaan dengan MRI pada organ-organ yang bergerak akan sangat sulit untuk dilakukan, karena akan menyebabkan kekaburan pada citra yang dihasilkan. Pemeriksaan MRI disekitar organ yang bergerak akan menimbulkan artefak yang mengganggu citra. Magnetic Resonance Cholangio Pancreatography merupakan salah satu pemeriksaan MRI pada organ yang bergerak, oleh karena itu diperlukan suatu teknik yang tepat untuk dapat menghindari atau meminimalisir kekaburan citra akibat pergerakan dari organ (Blake, 2010).

Pemeriksaan $M R C P$ terdapat dua teknik dalam proses akuisisi citra, yaitu akuisisi citra dengan teknik breath hold dan teknik trigger. Akuisisi citra pada teknik breath hold, berlangsung pada saat pasien menahan nafas. Tahan nafas ini bertujuan untuk menghindari adanya pergerakan dari organ abdomen sehingga mengakibatkan kekaburan citra. Teknik breath hold digunakan pada pasien yang kooperatif dan dapat menahan nafas saat pemeriksaan. Teknik breath hold dibagi menjadi dua bagian, yaitu single breath hold dan multi breath hold. Pada teknik single breath hold, untuk mendapatkan citra anatomi daerah yang dituju dilakukan dalam waktu satu kali akuisisi. Teknik ini dilakukan apabila pasien dapat menahan nafas dalam waktu yang cukup lama sekitar 20 detik. Proses akuisisi pada teknik multi breath hold untuk mendapatkan keseluruhan anatomi dilakukan dalam beberapa kali scanning. 
Tingkat kooperatif atau kerjasama antara petugas dengan pasien pada teknik breath hold sangat berpengaruh terhadap hasil citra yang dihasilkan untuk menghindari image blur.

Proses akuisisi tekniki trigger berlangsung dengan menggunakan suatu alat respiratory gatting yang diletakan pada diafragma pasien yang berfungsi untuk mendeteksi pernafasan pasien. Teknik trigger digunakan pada pasien yang tidak kooperatif dan pasien pediatrik, dimana pada kondisi ini pasien tidak dapat menahan nafas dengan baik. Akuisisi data pada teknik trigger berlangsung pada peralihan antara fase inspirasi dan ekspirasi, dimana saat fase peralihan inspirasi dan ekspirasi terdapat jeda waktu beberapa detik, pada fase itulah proses akuisisi berlangsung (Siemens, 2011).

Menurut Ehman (2004) pada teknik trigger terdapat dua macam mode, yaitu :

Yang pertama, Mode triggered (non-spin-AC), sequence spin echo yang berjalan pada time repetition (TR) yang dihidupkan dan dimatikan pada waktu yang tepat dalam siklus pernafasan yang terkontrol dalam sinyal dibox kontrol gatting. Dalam mode non spin AC, jaringan lunak menjadi objek pada waktu relaksasi ketika radiofrekuensi dimatikan oleh sistem gatting dapat menangkap gerak dari pernafasan.

Yang kedua, Mode triggered spin-conditioned, mode ini memerlukan hardware dan software (spin-conditioned) modus yang diperlukan lebih hardware yang menggantikan mode gatting non-AC. Dalam mode spin-conditioned, sequence spin echo berjalan terus menerus pada time repetition yang sedang berjalan. Mode tersebut memungkinkan sinyal dari sistem gatting yang digunakan untuk menentukan sekuen dari pernafasan pasien dan ditangkap oleh sistem dan disimpan dalam komputer untuk rekontruksi gambar. Dengan demikian, jaringan tidak diperbolehkan untuk waktu relaxation dalam periode yang lama karena data tidak dapat terekam. Sehingga metode spin-conditioned memerlukan ekspirasi dan inspirasi pasien yang stabil.

Pulse sequence yang digunakan pada MRCP yaitu Three Plane Localiser, Axial 2D Fiesta (Fat Suppressed), Coronal $2 D$ Fiesta (Fat Suppressed), Axial T2 Weighted Triggered, Coronal Oblique 3 Slab MRCP, Para Coronal Respiratory Triggered, Axial Thin Slice T2-Weighted dan Dynamic Coronal MRCP (Mandarano, 2008).

Teknik pemeriksaan MRCP pada sequence T2 Thick Slice Haste (breath hold) dan T2 Thick Slice Haste Trigger didapatkan hasil citra yang tidak jauh berbeda meskipun teknik pengambilan gambar yang berbeda. Sequence Half Fourier Acquisition Single Shot TSE (HASTE) juga sering dikenal dengan istilah Fast Advance Spine Sequence. Pada sekuen HASTE dapat digunakan sekuen Fast Spin Echo (FSE/TSE). Hanya saja pada sekuen Haste ini menggunakan Echo Train Length (ETL). Pada keadaan ini akan menghasilkan waktu scanning yang sangat cepat. Haste menggunakan Half Fourier Imaging (HFI) untuk proses akuisisi. Kombinasi dari ETL dan HFI akan mempengaruhi waktu scanning (Blink, 2004).

Half Fourier Acquisition Single Shot TSE didasarkan pada pengisian k-space yang tidak lengkap yaitu setengah pengisian dari k-space terpenuhi pada satu eksitasi pulsa RF sedangkan untuk data sisanya dapat dialihkan disebut singleshot. Istilah single shot juga berarti rangkaian pulsa RF $180^{\circ}$ yang mengikuti pulsa $90^{\circ}$ dan tidak terjadi lagi pengulangan pulsa $90^{\circ}$ (Weisthaupt, 2006).

Sekuen HASTE hanya dapat digunakan pada pembobotan T2 dikarenakan memiliki desain single shot. Jika nilai ETL-nya diperkecil maka akan menghasilkan citra pembobotan T1, akan tetapi citra ini tidak dapat dikatakan citra single-shot.

Teknik pemeriksaan MRCP pada sequence T2 Thick Slice Haste (breath hold) dan T2 Thick Slice Haste Trigger di Instalasi Radiologi Rumah Sakit Royal Taruma Jakarta dilakukan secara continue dan dokter radiologi di rumah sakit tersebut selalu membandingkan hasil citra dari kedua teknik tersebut pada potongan coronal slab. Instalasi Radiologi Rumah Sakit Umum Daerah dr. Saiful Anwar Malang dan Instalasi Radiologi Rumah Sakit Ken Saras Semarang juga menggunakan kedua teknik tersebut secara continue. Akan tetapi di Intalasi Radiologi Rumah Sakit Hasan Sadikin Bandung, Instalasi Radiologi Rumah Sakit Panti Rapih Yogyakarta dan Instalasi Radiologi Rumah Sakit Moewardi Surakarta pada pemeriksaan MRCP hanya dilakukan dengan menggunakan salah satu teknik breath hold atau trigger saja.

Penelitian ini dilakukan untuk mengetahui perbedaan informasi citra anatomi dan menentukan teknik terbaik dalam menghasilkan informasi citra anatomi antara teknik Breath Hold dan Trigger pada pemeriksaan Magnetic Resonannce Cholangeo Pancreatography menggunakan sequence T2 HASTE.

\section{METODE}

Penelitian ini adalah penelitian kuantitatif dengan pendekatan obsevasional. Variabel bebas dalam penelitian ini teknik breath hold dan trigger pada pemeriksaan MRCP, sedangkan variabel terikat adalah informasi citra anatomi menggunakan sequence T2 HASTE, sebagai variabel terkontrol adalah Time Repetition, Time Echo, Field of View, NEX dan slice thickness. Penelitian dilakukan pada bulan April sampai Mei 2016 di Instalasi Radiologi Rumah Sakit Royal Taruma Jakarta. Populasi dalam penelitian ini adalah seluruh pasien pemeriksaan MRCP di Instalasi Radiologi RS Royal Taruma Jakarta dengan sample penelitian pasien pemeriksaan MRCP berbagai klinis sejumlah 10 pasien.

Penelitian dilakukan dengan melakukan scanning pemeriksaan MRCP menggunakan sequence T2 HASTE. Setiap pasien dilakukan dua kali scanning yaitu dengan menggunakan teknik breath hold dan teknik trigger. Citra MRCP hasil dari masing-masing teknik scaning dilakukan penilaian yang menampakan kandung empedu dan duktusduktusnya. Penilaian informasi citra anatomi dilakukan oleh dokter spesialis radiologi yang berpengalaman membaca citra MRI minimal 2 tahun meliputi dukttus sistikus, duktus intra hepatikus, duktus hepatikus komunis, common bile duct, ductus pancreatikus dan gall blader dengan skala data ordinal berupa kejelasan Informasi Citra anatomi dengan nilai 1 untuk informasi citra tidak baik, 2 untuk hasil citra cukup baik dan 3 
untuk hasil citra baik. Sebagai control penilai dilakukan oleh radiolog yang lain dengan kualifikasi yang sama.

Analisis data dilakukan dengan uji Wilcoxon dengan tingkat signifikansi $95 \%$.

\section{HASIL}

Sejumlah 10 pasien terrlibat dalam penelitian ini dengan karakteristik 7 pasien laki-laki dan 3 pasien perempuan, umur 26-30 tahun sejumlah 2 pasien, 31-35 tahun sejumlah 4 pasien, 36-40 tahun sejumlah 1 pasien, 41-45 pasien sejumlah 1 pasien dan 46-50 tahun sejumlah 2 pasien. Contoh hasil citra pemeriksaan MRCP teknik breath hold dan trigger menggunakan sequence T2 HASTE coronal slab ditunjukan seperti pada gambar 1.

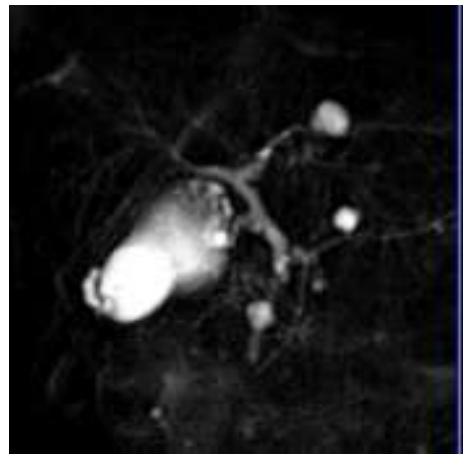

(a)

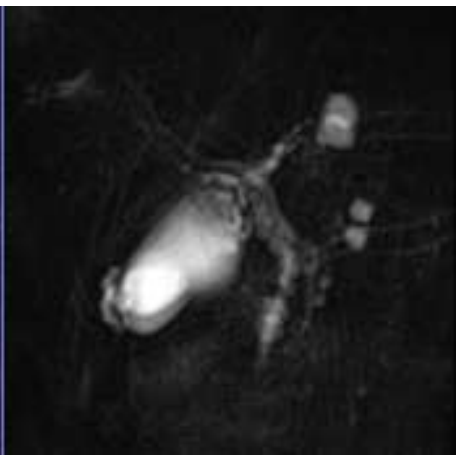

(b)
Gambar 1. Citra MRCP Sequence T2 HASTE (a) Teknik Trigger (b) Teknik Breath Hold

Hasil uji keselarasan (Kappa) antara dua penilai ditunjukan seperti tabel 1 .

Tabel 1. Kesesuain Hasil Pembacaan Citra

\begin{tabular}{cc} 
Tabel 1. Kesesuain Hasil Pembacaan Citra \\
\hline Teknik & $\begin{array}{c}\text { Koefisien } \\
\text { Kappa }\end{array}$ \\
\hline Breath Hold & 0,800 \\
Trigger & 0,737 \\
\hline
\end{tabular}

Hasil uji Kappa menunjukan terdapat keselarasan penilaian antara kedua responden dengan nilai koefisien Kappa teknik breath hold sebesar 0,800 dan trigger 0,737.

Uji beda informasi citra anatomi antara teknik breath hold dan trigger pada pemeriksaan MRCP ditunjukan seperti tabel 2.

Tabel 2. Perbedaan Informasi Citra Anatomi antara Teknik Breath Hold dan Trigger Secara Keseluruhan

\begin{tabular}{ccc}
\hline Teknik & Mean Rank & $p$-value \\
\hline Breath Hold & 0,00 & \multirow{2}{*}{0,011} \\
Trigger & 4,00 & \\
\hline
\end{tabular}

Uji beda menunjukan terdapat perbedaan informasi citra anatomi antara teknik breath hold dan trigger pada pemeriksaan MRCP menggunakan sequence T2 HASTE Coronal slab dengan nilai $p$-value 0,011 .
Teknik Trigger menghasilkan informasi citra anatomi yang lebih baik dibandingkan teknik breath hold dengan mean rank 4,00 .

Perbedaan informasi citra anatomi setiap bagian anatomi sistem billier antara teknik breath hold dan trigger pada pemeriksaan MRCP ditunjukan seperti tabel 3.

Tabel 3. Perbedaan Informasi Citra Anatomi per bagian antara Teknik Breath Hold dan Trigger Setiap Kriteria

\begin{tabular}{lc}
\hline \multicolumn{1}{c}{ Citra Anatomi } & p-value \\
\hline Duktus Sistikus & 0,023 \\
Duktus Intra Hepatikus & 0,034 \\
Duktus Hepatikus Komunis & 0,035 \\
Common Bile Duct & 0,025 \\
Duktus Pankreatikus & 0,180 \\
Gall Bladder & 0,025 \\
\hline
\end{tabular}

Uji beda menunjukan terdapat perbedaan informasi citra anatomi pada duktus sistikus (p-value 0,023), duktus intra hepatikus (p-value 0,034), duktus hepatikus komunis ( $\mathrm{p}$-value $0,035)$, common bille duct ( $\mathrm{p}$-value 0,025 ) dan gall bladder $(0,025)$. Tidak ada perbedaan informasi citra anatomi duktus pankreatikus antara teknik breath hold dan trigger (p-value 0,180 )

Untuk menentukan teknik terbaik dalam menghasilkan informasi citra anatomi antara teknik breath hold dan trigger dilihat dari nilai mean rank yang ditunjukan seperti tabel 4 .

Tabel 4. Hasil Uji Peringkat untuk Menetukan Teknik yang Terbaik

\begin{tabular}{lll}
\multicolumn{2}{c}{ Menghasilkan Informasi Citra Anatomi. } \\
\hline \multirow{2}{*}{ Citra Anatomi } & Teknik Pemeriksaan & $\begin{array}{c}\text { Mean } \\
\text { Rank }\end{array}$ \\
\hline \multirow{2}{*}{ Duktus Sistikus } & Breath Hold & 0,00 \\
& Trigger & 3,50 \\
Duktus Intra Hepatikus & Breath Hold & 0,00 \\
& Trigger & 3,00 \\
Duktus Hepatikus & Breath Hold & 4,00 \\
Komunis & Trigger & 4,57 \\
\multirow{3}{*}{ Common Bile Duct } & Breath Hold & 0,00 \\
& Trigger & 3,50 \\
Duktus Pankreatikus & Breath Hold & 0,00 \\
\multirow{3}{*}{ Gall Bladder } & Trigger & 1,50 \\
& Breath Hold & 0,00 \\
\hline
\end{tabular}

Hasil uji menunjukan teknik trigger mampu menghasilkan informasi citra yang lebih baik untuk duktus sistikus, duktus intra heptikus, duktus hepatikus komunis, common bile duct dan gall bladder. Teknik breath hold dapat 
dijadikan alternatif untuk memperlihatkan duktus pankreatikus karena tidak ada perbedaan informasi citra anatomi antara teknik breath hold dan trigger.

\section{DISKUSI}

Magnetic Resonance Cholangio Pancreatography merupakan pemeriksaan MRI yang digunakan untuk mengevaluasi duktus billiaris, pankreas dan kandung empedu dengan salurannya karena kemungkinan adanya batu, tumor dan penyakit lainnya (Mandarano, 2008). Pemeriksaan MRCP merupakan pemeriksaan yang cukup sulit karena merupakan pemeriksaan pada organ yang bergerak. Untuk menghindari kekaburan citra, pada pemeriksaan MRCP terdapat dua teknik pemeriksaan yaitu tahan nafas/breath hold dan trigger.

Hasil uji keselarasan (Kappa) menunjukan bahwa hasil agreement level teknik breath hold sebesar 0,800, sedangkan teknik trigger sebesar 0,737. Menurut Lisnur (2009) suatu ukuran kesepakatan antara dua penilai dalam mengklasifikan beberapa subjek ke dalam satu dari dua kategori dikatakan mufakat (objektif) jika nilai Coheen Kappa dalam rentang terendah 0,61 (substansial agreement) sampai dengan 1,00 (almost perfect agreement). Berdasarkan hasil uji Cross Tabulation (Kappa) tersebut maka dapat diketahui bahwa ada kesesuaian penilaian antara dokter responden dan dokter pembanding terhadap informasi citra anatomi antara teknik breath hold dan trigger pada pemeriksaan $M R C P$.

Hasil uji beda menunjukan terdapat perbedaan informasi citra anatomi dengan nilai p-value sebesar 0,011 pada tinggkat kepercayaan (confident level) 95\%. Uji beda setiap bagian anatomi Duktus Sistikus, Duktus Intra Hepatikus, Duktus Hepatikus Komunis, Common Bile Duct (CBD), dan Gall Bladder menunjukan terdapat perbedaan informasi citra anatomi antara teknik breath hold dan trigger, tetapi pada duktus pancreaticus menunjukan tidak ada perbedaan informasi citra anatomi. Tidak adanya perbedaan informasi citra anatomi duktus Pancreaticus disebabkan karena pada pemeriksaan MRCP dengan menggunakan sequence T2 HASTE coronal slab, dimana pada akuisisi arah irisan 20-30 derajat berpusat pada CBD, hanya sebagian (head of pancreas) yang terakuisisi sehingga citra dari duktus pancreaticus tergambar hypointens baik pada teknik breath hold maupun trigger.

Perbedaan informasi citra anatomi antara menggunakan teknik breath hold dan trigger pada pemeriksaan MRCP dengan menggunakan sequence T2 HASTE coronal slab dapat terjadi karena perbedaan periode pelaksanaan akuisisi data. Proses akuisisi data pada teknik breath hold dilakukan pada saat pasien melakukan tahan nafas, dimana pada saat pasien tahan nafas diharapkan tidak ada pergerakan dari organ abdomen karena pergerakan organ abdomen dapat menyebabkan kekaburan pada citra. Pada teknik breath hold kepatuhan pasien terhadap instruksi yang diberikan oleh petugas juga berpengaruh terhadap hasil citra. Menurut Glockner (2013), pada teknik breath hold kerja sama atau tingkat kooperatif pasien sangat dibutuhkan untuk menghindari image blur pada citra.
Pemeriksaan MRCP dengan menggunakan teknik breath hold biasanya dilakukan pada pasien kooperatif dan akuisisi dilakukan pada sekuen dengan waktu proses akuisisi sesingkat mungkin sehingga pasien tidak perlu menahan nafas terlalu lama.

Proses akuisisi data pada teknik trigger dilakukan dengan pasien nafas teratur dan akuisisi berlangsung pada saat peralihan antara fase inspirasi dan ekspirasi, dimana pada fase peralihan tersebut terdapat jeda dan pada saat jeda itulah pengaplikasian pulsa gatting diterapkan. Menurut Ehman (2004), teknik triggering sequence yang diaplikasikan pada Time Repetition (TR) yang di "on" dan di "off" kan pada waktu yang tepat dalam siklus pernafasan yang terkontrol dalam monitor kontrol sinyal gatting (gema navigator echo). Pada teknik trigger memungkinkan sinyal dari sistem gatting yang digunakan untuk menentukan akuisisi dari pernafasan pasien kemudian ditangkap oleh sistem dan disimpan dalam komputer untuk proses rekontruksi atau akuisisi gambar. Dalam proses akuisisi jaringan tidak diperbolehkan untuk beralaksasi dalam periode yang lama sehingga pasien memerlukan inspirasi dan ekspirasi yang stabil.

Pemeriksaan MRCP dengan menggunakan teknik trigger biasanya dilakukan pada pasien tidak kooperatif dan pediatrik serta pada sequence dengan waktu proses akuisisi data yang cukup lama sehingga tidak memungkinkan pasien menahan nafas untuk menghindari pergerakan organ abdomen.

Hasil uji peringkat baik setiap bagian anatomi maupun secara keseluruhan menunjukan hasil teknik trigger pada pemeriksaan MRCP dengan menggunakan sequence T2 HASTE mampu menghasilkan informasi citra anatomi yang lebih baik dibandingkan dengan teknik breath hold. Mean rank antara teknik breath hold dan trigger duktus Hepatikus Komunis menunjukan hasil mean rank yang tidak jauh berbeda meskipun teknik trigger memiliki nilai mean rank yang lebih tinggi. Hal ini disebabkan karena duktus Hepatikus komunis merupakan pertemuan dari percabangan duktus intra hepatikus dextra dan sinistra yang merupakan tunas ventral atau mesentrik ventral (pars hepatika) sehingga bagian kranial duktus hepatikus komunis lebih besar dengan diameter $0,4 \mathrm{~cm}$ sampai dengan $0,8 \mathrm{~cm}$.

Teknik trigger menghasilkan informasi citra anatomi yang lebih baik dibandingkan dengan teknik breath hold disebabkan karena pada teknik trigger dengan pengaplikasian pulsa gatting maka pergerakan nafas dari pasien dapat dimonitor sehingga proses akuisisi data dapat dilakukan dengan tepat pada saat peralihan antara fase inspirasi dan ekspirasi. Hal ini diperkuat oleh Azevedo (2011), pada teknik trigger pergerakan atau fase respirasi dapat diketahui dengan gema navigator, sehingga pada teknik trigger dapat memungkinkan sinkronisasi akusisi data dengan tepat ketika tidak ada pergerakan dari organ sehingga pada teknik trigger atau pengaplikasian pulsa gatting pada pemeriksaan $M R C P$ dapat mengurangi motion artefact dari pergerakan abdomen.

Menurut Glockner (2013), pengaplikasian Respiratory Gatting (triggering) pada pemeriksaan MRCP dapat menghasilkan citra dengan spasial resolusi lebih baik dan dengan nilai TE yang panjang akan dapat menekan organ 
disekitar dengan sangat baik sehingga sistem biller akan tervisualisasi dengan baik.

\section{SIMPULAN}

Terdapat perbedaan informasi citra anatomi antara teknik breath hold dan trigger pada pemeriksaan Magnetic Resonance Cholangio Pancreatography (MRCP) menggunakan sequence T2 Half Fourier Aquisition Single Shot TSE (HASTE) coronal slab dengan nilai p-value 0,011 dengan tingkat kepercayaan 95\%. Teknik trigger menghasilkan informasi citra anatomi yang lebih baik dibandingkan dengan teknik breath hold.

\section{DAFTAR PUSTAKA}

Azevedo, Rafael M. 2011. Free-breathing 3D TI-Weighted Gradient-Echo Sequence With Radial Data Sampling in Abdominal MRI: Preliminary Observations. Chapel Hill: California University.

Blake, A Michael, et all. 2010. Adrenal Imaging. St. Boston: Harvard Medical School.

Blink, Evert J. 2004. Basic MRI Physics For Anyone Who Does Not Have a Degree In Physics. Germany.

Ehman, Richard L, 2004. Magnetic Resonance Imaging with Respiratory Gating. San Fransisco: Techniques and Advantages. University of California School Medicine.

Glockner, James F, 2014. Breath-held MR Cholangiopancreatography (MRCP) Using a 2D Dixion Fat-Water Separated Balanced Steady Free Precession sequence. USA: HHS Public Acces NCBI.

Lisnur, Wachidah, 2009. Keberartian Koefisien Raw Agreement Coheen Kappa. Bandung.

Mandarano, G. 2008. The Diagnostic MRCP Examination: Overcoming Technical Challenges to Ensure Clinical Succes. radiographics.rsna.org diakses tanggal 29 Februari 2016.

Siemens. 2011. Abdominal Imaging Aplication Brochure. Germany : Magnetom Esensa.

Siemens. 2011. How to Learn MRI An Illustrated Workbook, Exercise 7: $M R C P$. Germany: Magnetom Esensa. 